International Journal of Trend in Scientific Research and Development (IJTSRD)

Volume: 3 | Issue: 3 | Mar-Apr 2019 Available Online: www.ijtsrd.com e-ISSN: 2456 - 6470

\title{
Automatic Car Washing and Drying using Microcontroller 8051
}

\author{
Satbhai Sneha Nitin, Gavhane Pamabai Raghunath, Dharmadhikari Rushikesh Vinayak \\ Lecturer, Department of Electronics \& Telecommunication Engineering, \\ P.Dr.V.V. Patil Institute of Technology \& Engineering (Polytechnic), Loni, Maharashtra, India
}

\begin{abstract}
How to cite this paper: Satbhai Sneha Nitin | Gavhane Pamabai Raghunath | Dharmadhikari Rushikesh Vinayak "Automatic Car Washing and Drying using Microcontroller 8051" Published in International Journal of Trend in Scientific Research and Development (ijtsrd), ISSN: 24566470, Volume-3 | Issue-3, April 2019, pp.1544-1546, URL: https://www.ijtsrd.c om/papers/ijtsrd23 433.pdf

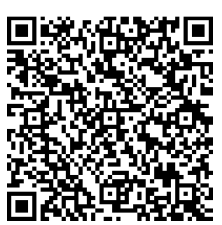

IITSRD23433

Copyright (C) 2019 by author(s) and International Journal of Trend in Scientific Research and Development Journal. This is an Open Access article distributed under the terms of the Creative Commons Attribution License (CC BY 4.0)

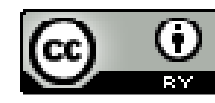

(http://creativecommons.org/licenses/ by/4.0)

\section{INTRODUCTION}

As compared to the foreign countries this system is used in very less no. of cities in India because of its cost and complexity. But we have tried to minimize it according to the device list which will be definitely helpful for our project.

The first automatic car washes appeared in the late 1930s. Automatic car washes consist of tunnel-like buildings into which customers (or attendants) drive. Some car washes have their customers pay through a computerized, also known as an "automatic cashier". The mechanism inputs the wash PLU into a master computer or a tunnel controller automatically. When the sale is automated, after paying the car is put into a line-up often called the stack or queue. The stack moves sequentially, so the wash knows what each car purchased. After pulling up to the tunnel entrance, an attendant usually guides the customer onto the track or conveyor. At some washes, both tires will pass over a tire sensor, and the system will send several rollers. The tire sensor lets the wash know where the wheels are and how far apart they are. On other systems the employee may guide the customer on and hit a 'Send Car' button on the tunnel controller, to manually send the rollers which push the car through. When the customer is on the conveyor, the attendant will instruct the customer to put the vehicle into neutral, release all brakes, and refrain from steering. Failure to do so can cause an accident on the conveyor. The rollers come up behind the tires, pushing the car through a detector, which measures vehicle length, allowing the controller to tailor the wash to each individual vehicle. The equipment frame, or arches, varies in number and type. A good car wash makes use of many different pieces of equipment and stages of chemical application to thoroughly clean the vehicle.

\section{BLOCK DIAGRAM:} BLOCK DIAGRAM: -

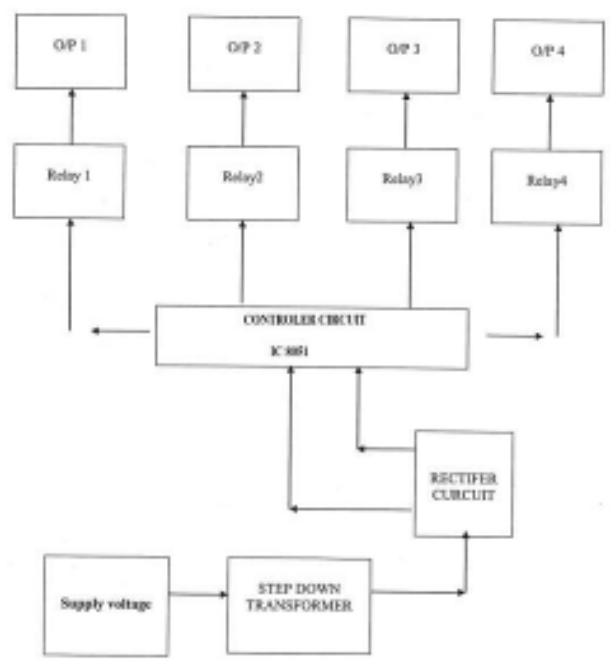

Fig. block diagram 


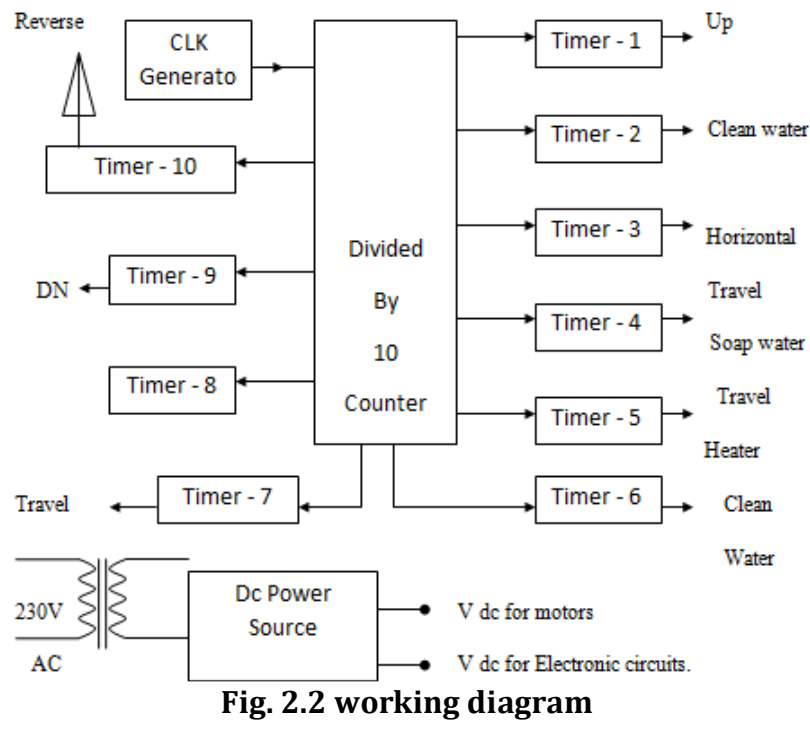

Automatic Car-Washer and dryer is controlled using the electro-mechanical system as shown. A proto-type model is implemented in our project. The mechanism includes the lifting of parallel car and moving it in a forward direction in steps. At intermediate steps the car cleaning water in pure form and soap water is allowed to fall on the car under wash. Care is taken for not allowing the water to fall on the assembly. At the end the car lifted is again allowed to come down and the parallel. Returns back for loading a new car. The system can be divided in two different sections.

1. Mechanical Assembly.

2. Electrical Control

\section{MECHANICAL ASSEMBLY}

The mechanical assembly consists of two dc motors with gear assembly with it. This gear assembly reduces the revolutions per minute of the motor and it increase the torque that is the driving power of the system. As shown in assembly, first motor is for lifting the car pallet in upward direction i.e. a but and bolt assembly is used here. The threaded bolt is bored at its head side and the motor shaft is inserted inside the fixed properly. The motor is fixed on a base, which is also movable, but with another motor. If the motor with bolt assembly is started the bolt rotates in one direction. And being a dc motor if the supply polarities are interchanged, then the motor and the bolt rotates in opposite direction.

A bolt which is suitable for nut is used. If the bolt motor assembly rotates the, nut also rotates in anti-clockwise direction. Since the motor and bolt assembly is steady, the nut travels in upward direction and downward direction, as the motor rotates in clockwise and anti-clockwise respectively.

Thus this is the lifting mechanism. After lifting the horizontal travel of the pallet starts. This movement is done by another dc motor. This dc motor is also provided with gears, which reduces the speed and increases the power of the system.

A rack and Pinter gear assembly is used here. One horizontal gear is placed at the bottom of the assembly and the shaft with gear assembly of the motor is aligned in such a way that. The motor rotates in one direction it travels along the horizontal gear in horizontal directions. The pallet with the vertical motor assembly is mounted on this horizontally traveling motor. This assembly also moves along with the motor. Thus, the motor is operated in steps and thus, the traveling is also done in steps. In four different steps the four different functions are done.

Immediate after lifting, the clean water supply is started and then the trolley movement. i.e. travel starts, and then at another stage, the soap water is allowed to fall on the car. After the specified time this soap water stops and again the clean water is allowed to fall on the car. After specified time as above, the different types of waters different water tanks with electric motor pumps are provided. These pumps are made on at appropriate time and off at appropriate time. These tanks are mounted on separate stands along with the assembly. After passing through different types of cleaning waters, the car is dried in a separate chamber and then the horizontal motor stops and the vertical lifting motors starts and rotates in opposite direction than the first movement. The nut assembly with the car pallet comes down. Then the horizontal traveling motor is on with reversed supply polarity and the travel starts in opposite direction. The horizontal pallet moves in back word direction. The pallet comes at its original position, from where the next car can be loaded for washing purpose.

\section{MICROCONTROLLER}

The 8051 is a low-power, high-performance CMOS 8-bit microcomputer with $4 \mathrm{~K}$ bytes of Flash programmable and erasable read only memory (PEROM). The device is manufactured using Atmel's high-density nonvolatile memory technology and is compatible with the industrystandard MCS-51 instruction set and pin out. The on-chip Flash allows the program memory to be reprogrammed insystem or by a conventional nonvolatile memory programmer. By combining a versatile 8-bit CPU with Flash on a monolithic chip, the microcontroller 8051 is a powerful microcomputer which provides a highly-flexible and costeffective solution to many embedded control applications.

\section{CIRCUIT DIAGRAM}

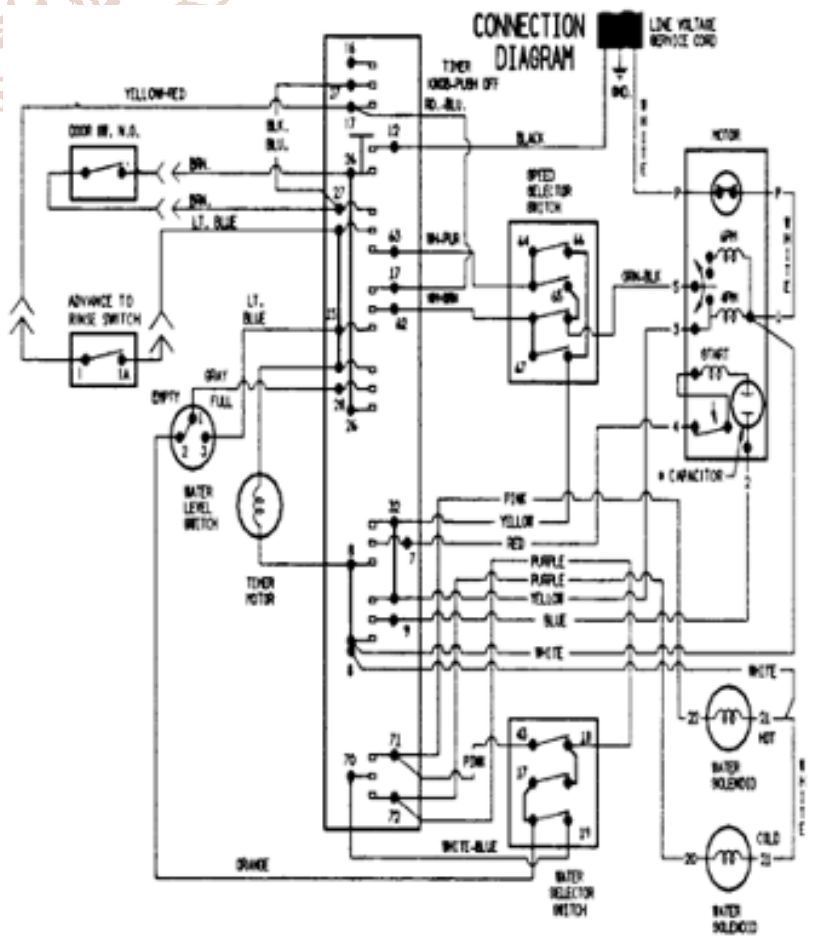




\section{CIRCUIT EXPLANATION}

The circuit diagram consists of a clock generator. Then divide by 10 counters $\&$ the dc regulated power supply. The power supply is developed using step down transformer, rectifier, filter and voltage regulators.

The clock generator is IC 89c51 in as able mode. When powered with dc supply, starts oscillating. The time span between two successive pulses is determined with the help of potentiometer provided on the CKT.

The output pulse is given to divide by 10 decade counter, which outputs the pulses in sequential manner.

When it receives first pulse, the first output Q0 of the counter is high and all other outputs are low. The high output switches $\mathrm{ON}$ a transistor which switches on a relay. This relay provides the supply to the motor.

When next pulses arrive the 2nd output of the counter goes high and the logic repeats for all the 10 outputs.

\section{ADVANTAGES}

1. The whole system is automatic so no manpower required.

2. If we use special car washing pressure pumps no compressor will required.

3. Can be use in domestic service stations, as there is no compressor \& no. loud noise.

4. Very less maintenance.

5. Comparatively cost of system is less.

6. No. more space required.

7. No. environmental pollution.

\section{APPLICATIONS}

1. In car manufacturing companies.-After assembly of car.

2. In service stations.

3. Car replacing and maintaining stations

4. Car body building industry

\section{LIMITATIONS}

1. Electric Power Will Require Running The System.

\section{RESULT}

In Automatic Car Washing System, we performed all the operations needed to clean the car fruitfully by using Microcontroller after achievement of the above processes by mechanism of this system car washing will be cost effective, time saving and pollution free. By using this process we can clean up the car up to $95 \%$.

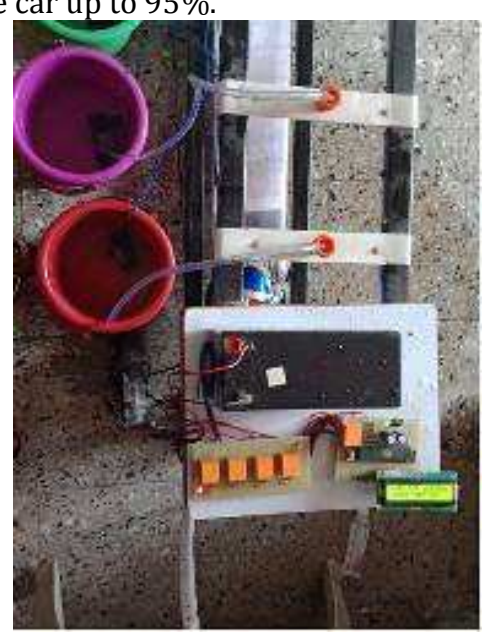

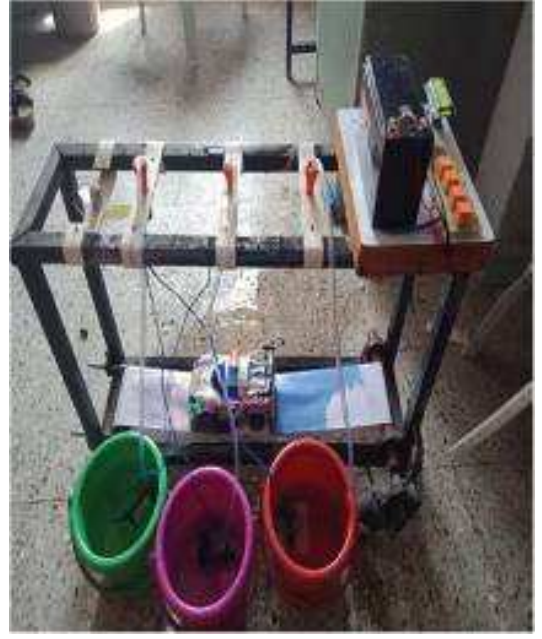

\section{CONCLUSION}

After completion of the paper, auto car washer and dryer,we can come to conclusion that such automation system are quite beneficial , and saving time of operation and also man power reduced ,improving the economy of the system. The future such type of system will have more demanded.

\section{REFERENCES}

[1] Mr. Bambare Tejas, Ms. Bondre Varsha, Mr. Kapse Manoj, Mr. Khairnar Ketan, Mr. Kotkar,2017, Automatic car washing and drying system Vol. 5, Issue 02, 2017

[2] Zeenal Lalluwadia, Nidhi Bhatia, Jayana Rana, Automatic car washing system using MICROCONTROLLER , Vol.4 ,Issue April,2016

[3] Prof. Mhaske ,D.A. Bhavthankar, R.G. Darade D.J., MICROCONTROLLER Based Car Washing System, Vol.4 ,Issue April 2016

[4] Vivek Kumar Yadav, Suryansh Tyagi, Gulshan Kumar, Nishant Kumar, Swapnil Namekar, Automatic Car Washing using, MICROCONTROLLER,Vol 6, Issue 2016

[5] Seyyed M. M. Sabet, Design of a Drying System for a Rollover Carwash Machine using CFD, Vol.3 ,Issue 04 october,2016

[6] Pranoti Utekar, Sayali Naik, Monika Wadekar and S.G. Watve, Implementation of Auto car washing system using two robotic arm, Vol 3, Issue2015 